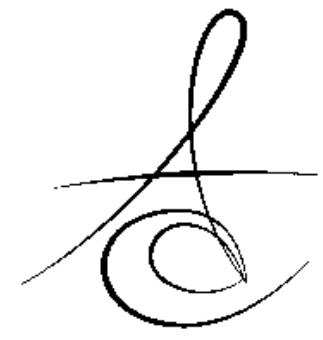

\title{
ÖN BÖLGE ESTETİĞİNİN PROTETİK RESTORASYONLARLA DÜZENLENMESİ: ALTI OLGU SUNUMU ${ }^{*}$
}

\author{
EDITING THE FRONT REGION AESTHETICS WITH PROSTHETIC \\ RESTORATION: SIX CASES REPORT ${ }^{\neq}$
}

Dt. Özlem ÖZBAYRAM*

Prof.Dr.Nuran YANIKOĞLU *

Makale Kodu/Article code: 2693

Makale Gönderilme tarihi: 22.03.2016

Kabul Tarihi: 12.04.2016

\section{öz}

Ön bölgedeki diş anomalileri, dişlerin renklenmesi, şekil ve pozisyon bozuklukları, morfolojik değişiklikler estetik sorunlara yol açabilmektedir. Ayrıca periodontal hastalık ya da travma nedeniyle meydana gelen diş kayıpları hastaları rahatsız eden diğer bir sorundur. Ön bölgedeki bu problemlerle ilgili olarak olumlu sonuç elde edebilmek için multidisipliner tedavi yaklaşımı gerekli olabilir. Şekil ve renk bozukluklarında çeşitli kuronlar yapılabildiği gibi, diş eksikliğinde de adeziv köprü, geleneksel köprü ve implant ile düzenlemeler yapılabilir.

Bu çalışmada estetik şikayetlerinden dolayı kliniğe başvuran hastalara multidisipliner yaklaşımlarla; tedavi, endodonti, cerrahi işbirliği ile metal-porselen, tam seramik kuronlar ve geleneksel köprü restorasyonları hazırlanmıştır.

Anahtar kelimeler: Estetik, tam seramik, metal seramik köprü.

\section{ABSTRACT}

Dental anomalies in the anterior region, discoloration of the teeth, shape and position disorder, due to morphological changes that can cause aesthetic problems. In addition, periodontal disease or tooth lossing occurs because of trauma is another problem that bothered patients. Multidisciplinary treatment can be necessary to obtain positive results about these anterior esthetic problems. As various crowns can be made on shape and color disorder, tooth missing can be regulated with conventional bridges and implants.

In this study, different prosthetic restorations are prepared to the patient admitted to clinic due to aesthetic complaints with multidisciplinary approach.

Key words: Esthetic, all ceramic, metal ceramic bridge

\section{GİRİş}

Ön bölgedeki diş anomalileri, renklenmeler, şekil ve pozisyon bozukluğu, morfolojik değişiklikler estetik sorunlara yol açabilmektedir. Ayrıca periodontal hastalık ya da travma nedeniyle de meydana gelen diş kayıpları hastaları rahatsız eden diğer bir problemdir. ${ }^{1}$ Dental travma sonucu üst çene ön bölge ${ }^{2}$, en sık da kesici dişler ${ }^{3}$ etkilenmektedir. Ön bölgedeki bu problemlerin tedavisinde multidisipliner yaklaşım gerekli olabilir. Multidisipliner tedavi; cerrahi girişimler, ortodontik tedavi, endodontik tedavi, periodontal tedavi ve protetik tedaviyi içermektedir. ${ }^{4}$ Estetik amaç- la yapılan restorasyonlarda doğal dişlerin ömrünün uzatılması için konservatif tedavi yaklaşımı benimsenmelidir. Restoratif dental materyallerdeki gelişmelerin sayesinde estetik restorasyonlardaki konservatif yaklaşımlar popülerlik kazanmaktadır. ${ }^{5-7}$

Diş hekimliğinde en zor tedavilerden biri de ön bölge diş kayıplarında estetiğin yeniden sağlanılmasıdır ve bunun için de dental porselenlerden yararlanılmaktadır. ${ }^{1,8}$ Diş eksiklikleri adeziv köprü, geleneksel köprü ve implant ile tedavi edilebilir. ${ }^{9-11}$

Son 40 yıl boyunca metal destekli köprüler sabit protezler için güvenilir bir tedavi seçeneği olmuştur. ${ }^{12}$ $\mathrm{Bu}$ protez seçeneğinde porselen estetiği sağlarken;

*Atatürk Üniversitesi Diş Hekimliği Fakültesi, Protetik Diş Tedavisi AD, Erzurum ${ }^{1}$

${ }^{7}$ Bu makale 5.Uluslararası Türk Prostodonti ve Implantoloji Derneği Bilimsel Sempozyumu'nda poster olarak sunulmuştur. 18-20 Mart 2016/Erzurum-Türkiye 
Atatürk Üniv. Diş Hek. Fak. Derg.

J Dent Fac Atatürk Uni

Supplement: 16, Yıl: 2016, Sayfa : 42-45
ÖZBAYRAM,

YANIKOĞLU, DİNÇKAL metal kısmı da porselene desteklik sağlamaktadır. ${ }^{13}$ Metal seramik restorasyonlar diş hekimliğinde rutin olarak kullanılmaktadır ancak çoğu hastada estetiği yeterince sağlayamamaktadır. ${ }^{14}$ Estetik beklentilerin giderek artması diş hekimliğinde metal içermeyen sistemlerin ve adeziv simantasyon prosedürlerinin gelişmesine yol açmıştır. ${ }^{15}$

Bu çalışmada, estetik şikayetlerinden dolayı kliniğe başvuran hastaların tedavileri multidisipliner yaklaşım sonrası protetik restorasyonlarla tamamlandı.

\section{OLGU SUNUMU}

\section{OLGU 1}

Kliniğe başvuran 35 yaşındaki erkek hastanın yapılan ağız içi muayenesinde dişlerinde çapraşıklık ve maksiller sol lateral dişinin palatinale deplase olduğu görüldü. Mesleği gereği fonasyon konusunda kısa sürede çözümlenecek bir tedavi şekli isteyen hastaya maddi durumu ve süre sıkıntısı da göz önünde bulundurularak metal destekli porselen restorasyon planlandı. Periodontal tedavi sonrası oral hijyeni sağlandı. Preparasyon öncesi maksiller sol santral dişine endodontik tedavi yapıldı ve daha sonra maksiller santral dişler ve sol lateral dişleri prepare edildi. Hasta diş eti seviyelemesi için gingivoplasti yaptırmak istemedi. Final restorasyonda maksiller sol lateral dişin kuron boyunu maksiller sağ santral ile eşitlemek için dişeti porseleni kullanıldı. Hastadan onay alınıp okluzyon kontrolü sonrası kuronlar polikarboksilat simanla (Durelon; 3M ESPE, İstanbul, Türkiye) simante edildi. Hasta bu protetik yaklaşımdan memnun kaldı (Şekil $1 \mathrm{a}, \mathrm{b}$ ).

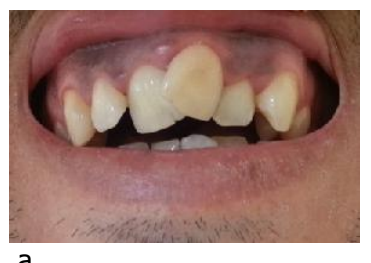

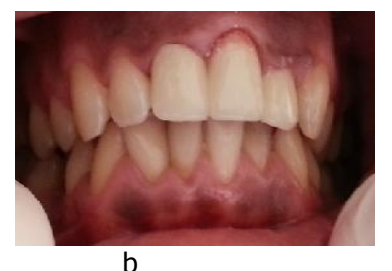

Şekil $1 \mathrm{a}, \mathrm{b}$ : Olgunun restorasyon öncesi ve sonrası hali

\section{OLGU 2}

Kliniğe başvuran 22 yaşındaki bayan hastanın ağız içi muayenesinde oral hijyen eksikliği, diastemalar ve açık kapanış (open bite) (4 mm) olduğu görüldü. Alınan anamnezde, hasta estetik olarak rahatsız olduğunu ve bazı sesleri düzgün telaffuz edemediğini dile getirdi. Ortodonti bölümüyle yapılan konsültasyon sonucu, büyüme ve gelişimini tamamlamış olan hastaya open bite tedavisi için yer darlığından dolayı önce- likle ortodontik olarak maksiller genişletme yapılması gerektiği anlatıldı. Gerekli periodontal tedavi sonrası ortodontik tedaviyi istemeyen hasta için protetik tedavi planlandı. Final restorasyonu görmek amacıyla wax-up yapıldı. Maksiller ve mandibuler kanin dişleri arası prepare edildi. Open bite'ı kapatmak için maksiller dişleri 2,5 mm, mandibular dişleri de 1,5 mm uzatılacak şekilde restorasyon hazırlandı. Metal destekli porselen restorasyon okluzyon kontrolü sonrası polikarboksilat simanla (Durelon; 3M ESPE, İstanbul, Türkiye) simante edildi (Şekil 2 a,b).

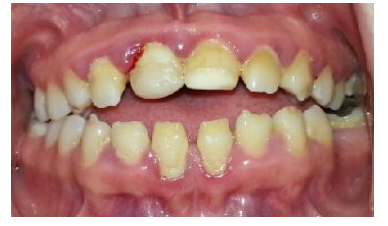

a

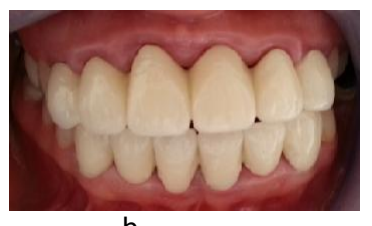

b
Şekil 2 a,b: Olgunun restorasyon öncesi ve sonrası hali

\section{OLGU 3}

Kliniğe başvuran 50 yaşındaki erkek hastanın ağız içi muayenesinde diş eksiklikleri, çürük, yalancı prognati, dikey boyut kaybı ve bruksizm sonrası mine tabakasının aşınmış olduğu görüldü. Hastada hassasiyet şikayeti olduğu öğrenildi. Dişler prepare edildikten sonra geçici restorasyon ile okluzyon kademeli olarak yükseltildi. 3 ay geçici restorasyon kullanılıp TME' nin duruma adapte olması sağlandı. Daha sonra geçici restorasyonlara akril ilavesi yapılarak okluzyon $3 \mathrm{~mm}$ daha yükseltildi. Bruksizm nedeniyle diş boşlukları için implant kontredike bir tedavi seçeneğiydi. Ekonomik sebeplerden dolayı tam seramik yaptırmak istemeyen hastaya final restorasyon olarak metal-porselen restorasyon yapıldı ve okluzyon kontrolü sonrası polikarboksilat simanla (Durelon; 3M ESPE, İstanbul, Türkiye) simante edildi (Şekil $3 \mathrm{a}, \mathrm{b}, \mathrm{c}$ ).

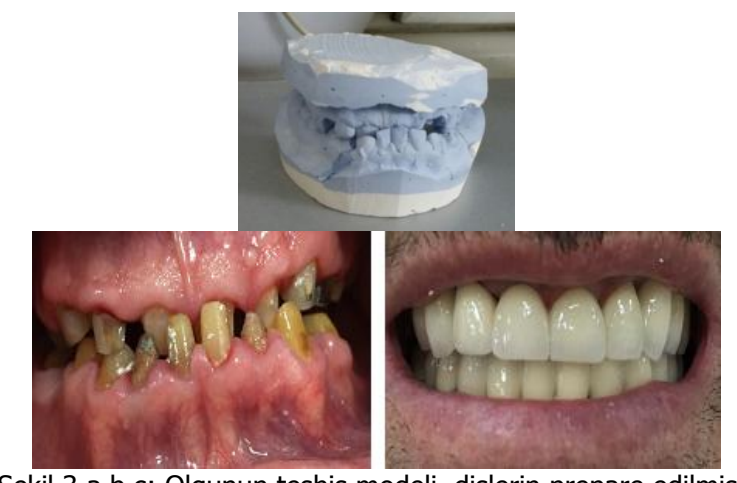

Şekil 3 a,b,c: Olgunun teşhis modeli, dişlerin prepare edilmiş hali ve restorasyon sonrası hali

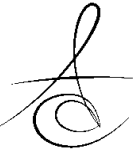


Atatürk Üniv. Diş Hek. Fak. Derg.

J Dent Fac Atatürk Uni

Supplement: 16, Yıl: 2016, Sayfa : 42-45

\section{OLGU 4}

Kliniğe başvuran 21 yaşındaki erkek hastanın ağız içi muayenesinde; oral hijyenin kötü olduğu ve maksilladaki santral dişlerinde dikey ve yatay mobilite görüldü. Hastadan alınan anamnezde beş sene önce ön bölgeden travma aldığı öğrenildi. Travma sonrası dişlerde kök rezorpsiyonu olduğu için maksiller santral dişlere çekim endikasyonu konuldu. Yara bölgesinin iyileşmesini takiben vestibül kemiğin rezorbe olduğu, yeterli kaide desteği olmadığı için estetiğin istenilen düzeyde implantla sağlanamayacağı hastaya bildirildi. Lateral dişler destek alınarak tam seramik sistemlerden zirkon alt yapılı seramik restorasyon (Lava;3M Espe Dental AG, Seefeld, Almanya) hazırlandı ve okluzyon kontrolü sonrası polikarboksilat simanla (Durelon; 3M ESPE, İstanbul, Türkiye) simante edildi (Şekil 4 a,b).
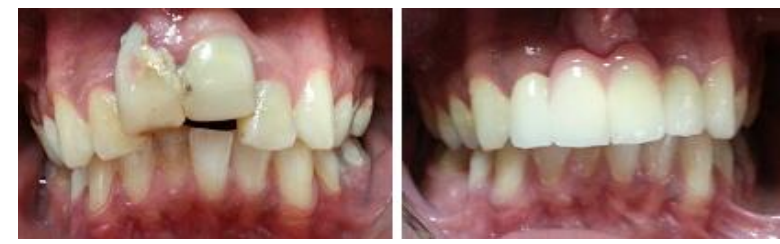

Şekil 4 a,b: Olgunun restorasyon öncesi ve sonrası hali

\section{OLGU 5}

Kliniğe başvuran 51 yaşındaki bayan hastanın ağız içi muayenesinde maksiller ön bölgede aşırı overjet ve dişlerde mobilite görüldü. Alınan anamnezde hastanın dudağını zorlayarak ağzını kapattığı ve gülmesinin etkilendiği görüldü. Dişlerin vestibüllerinden daha fazla preparasyon yapılarak aşırı vestibüler taşkınlık azaltıldı. Dişlerdeki mobiliteden dolayı final restorasyon birbirine bağlı kuronlar şeklinde planlandı ve bu sayede dişlere periodontal splintleme yapılmış oldu. Restorasyon için tam seramik sistemlerden zirkon (Lava;3M Espe Dental AG, Seefeld, Almanya) kullanıldı. Okluzyon kontrolü sonrası polikarboksilat simanla (Durelon; 3M ESPE, İstanbul, Türkiye) simante edildi (Şekil 5 a,b).
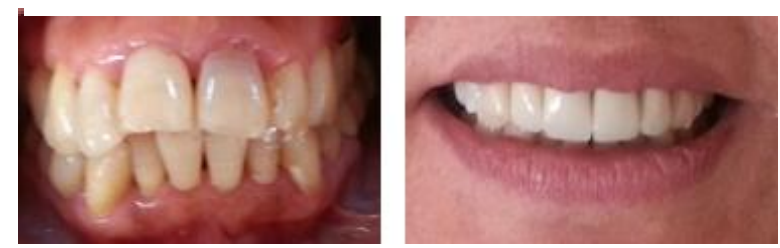

Şekil 5 a,b: Olgunun restorasyon öncesi ve sonrası hali
ÖZBAYRAM,

YANIKOĞLU, DİNÇKAL

\section{OLGU 6}

Kliniğe başvuran 27 yaşındaki bayan hastanın ağız içi muayenesinde; oral hijyen eksikliği, maksiller lateral dişlerinde rotasyon ve diastemalar olduğu ve hastanın bundan etkilendiği öğrenildi. Periodontal tedavi sonrası oral hijyen motivasyonu verildi. Çekimsiz tedavi planlandığı için lateral dişlerin konumundan dolayı preparasyon öncesi endodontik tedavi yapılması uygun görüldü. Santral dişlerin distalinden, lateral dişlerinde mezialinden fazla kesim yapılarak lateral ve santral diş arasına lateral diş için yer açıldı. Lateral dişlere de kanin formu verildi. Köprü restorasyonu IPS e.max Press (Ivoclar Vivadent, Schaan, Liechtenstein ) ile yapıldı ve okluzyon kontrolü sonrası adeziv simanla NX3 Nexus $^{\circledR}$ (Kerr Corporation, Kaliforniya, ABD) simante edildi (Şekil 6 a,b).

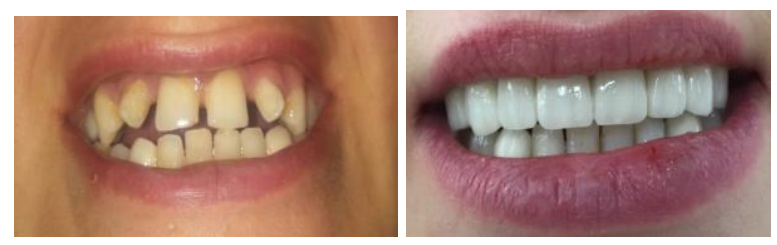

Şekil 6 a,b: Olgunun restorasyon öncesi ve sonrası hali

\section{TARTIŞMA}

Protez yapımına karar verirken diş hekimi mevcut dişlerin sayısını, periodontal durumunu, pozisyonunu ve oral hijyeni göz önüne alarak, hastanın estetik intiyaçları ve maddi durumunu da değerlendirilerek planlama yapmalıdır. ${ }^{16}$ İmplant destekli protezler, hareketli protezler, geleneksel metal destekli köprüler, tam seramikler ve konservatif preparasyon prensiplerine bağlı kalınarak yapılan adeziv köprüler anterior diş kayıplarında alternatif tedavi seçeneklerindendir. ${ }^{17}$

Metal seramik köprüler günümüzde yaygın olarak kullanılmaktadır. Ancak estetiğe karşı artan talep diş hekimlerini özellikle üst çene anterior dişlerin restorasyonunda daha estetik olan tam seramik materyallerine yönlendirmiştir. ${ }^{18}$ Metal-porselen restorasyonlara göre, tam seramik restorasyonlar gelişmiş ışık geçirgenliklerine bağlı olarak yüksek estetik potansiyele sahiptirler. ${ }^{19}$ Ayrıca tam seramikler çevre dokularla biyouyumlu ve fonksiyonel stresleri tolere edebilecek mekanik özelliklere sahiptirler. ${ }^{20,21}$

Kurallarına uygun olarak yapılan protetik restorasyonlar hastalarda yeterli estetik, fonasyon ve fonksiyonu sağlayacaktır.

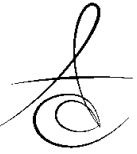


Atatürk Üniv. Diş Hek. Fak. Derg.

J Dent Fac Atatürk Uni

Supplement: 16, Yıl: 2016, Sayfa : 42-45
ÖZBAYRAM,

YANIKOĞLU, DİNÇKAL

\section{SONUÇ}

Bu çalışmada, erişkin bireylerde multidisipliner yaklaşımla estetik düzenlemeler yapılan vakalar sunulmuştur. Hastalar uygulanan tedavileri estetik, fonasyon ve fonksiyon açısından memnun edici bulmuşlardır.

\section{KAYNAKLAR}

1. Belser UC, Magne P, Magne M. Ceramic laminate veneers: continuous evolution of indications. J Esthet Dent, 1997; 9: 197-207.

2. Artun J, Behbehani F, Al-Jame B, Kerosuo $\mathrm{H}$. Incisor trauma in an adolescent Arab population: prevalence, severity, and occlusal risk factors. Am J Orthod Dentofacial Orthop, 2005; 128: 347-52.

3. Soriano EP, Caldas Ade F, Jr., Diniz De Carvalho MV, Amorim Filho Hde A. Prevalence and risk factors related to traumatic dental injuries in Brazilian schoolchildren. Dent Traumatol, 2007; 23: 232-40.

4. Luiz FP, Accácio LdV, Thiago AP, Karyna MVC, Vidotti HA. Resolution of complex esthetic problems in abnormal anterior teeth: A clinical report. J Prosthet Dent, 2014;112:94-8.

5. Conrad HJ, Seong WJ, Pesun IJ. Current ceramic materials and systems with clinical recommendations: a systematic review. J Prosthet Dent, 2007; 98: 389-404.

6. Ozturk E, Bolay S, Hickel R, Ilie N. Shear bond strength of porcelain laminate veneers to enamel, dentine and enamel-dentine complex bonded with different adhesive luting systems. J Dent, 2013; 41: 97-105.

7. Jang JH, Lee SH, Paek J, Kim SY. Splinted Porcelain Laminate Veneers With a Natural Tooth Pontic: A Provisional Approach for Conservative and Esthetic Treatment of a Challenging Case. Oper Dent, 2015; 40: E257-65.

8. Strassler HE. Minimally invasive porcelain veneers: indications for a conservative esthetic dentistry treatment modality. Gen Dent, 2007; 55: 686-694; quiz 695-686, 712.

9. Livaditis GJ. Cast metal resin-bonded retainers for posterior teeth. J Am Dent Assoc 1980;101: 926-9.

10. Hussey DL, Pagni C, Linden GJ. Performance of 400 Adhesive Bridges Fitted in a Restorative Dentistry Department. J Dent, 1991; 19: 221-5.
11. Weng D, Ries S, Richter EJ. Treatment of a juvenile patient with a maxillary all ceramic resinbonded fixed partial denture: a case report. Quintessence Int.2002; 33: 584-8.

12. Guess PC, Kulis A, Witkowski S, Wolkewitz M, Zhang Y, Strub JR. Shear bond strengths between different zirconia cores and veneering ceramics and their susceptibility to thermocycling. Dent Mater, 2008; 24: 1556-1567.

13. Lu Y, Chen W, Ke W, Wu S. Nickel-based ( $\mathrm{Ni}-\mathrm{Cr}$ and $\mathrm{Ni}-\mathrm{Cr}-\mathrm{Be}$ ) alloys used in dental restorations may be a potential cause for immune-mediated hypersensitivity. Med Hypotheses 2009; 73: 716-7.

14. Hasssija J, Hegde V, Sridhar N. An In Vitro Study on Effect of Ceramic Thickness and Multiple Firings on Colour of Metal Ceramic Restorations. J Indian Prosthodont Soc, 2014; 14: 86-92.

15. Vichi A, Sedda M, Bonadeo G, Bosco M, Barbiera A, Tsintsadze N, Carrabba $M$, Ferrari $M$. Effect of repeated firings on flexural strength of veneered zirconia. Dent Mater, 2015; 31: e151-6.

16. Wenz HJ, Hertrampf K, Lehmann KM. Clinical longevity of removable partial dentures retained by telescopic crowns: outcome of the double crown with clearance fit. Int J Prosthodont, 2001; 14: 207-13.

17. Belli S, Ozer F. A Simple Method for Single Anterior Tooth Replacement. J Adhes Dent 2000; 2: 67-70.

18. Pollington $S$. Novel glass-ceramics for dental restorations. J Contemp Dent Pract 2011;12: 60-7.

19. Castellani D, Baccetti T, Giovannoni A, Bernardini UD. Resistance to fracture of metal ceramic and all-ceramic crowns. Int J Prosthodont, 1994; 7: 149-54.

20. Neiva G, Yaman P, Dennison JB, Razzoog ME, Lang BR. Resistance of fracture of three all ceramic systems. J Esthet Dent.1998; 10:60-6.

21 Yalım B, Türker SB. Klinikte tam seramik sistemler. Atatürk Üniv Diş Hek Fak Derg 2012;5:76-90

\author{
Yazışma Adresi \\ Dt. Özlem ÖZBAYRAM \\ Atatürk Üniversitesi Diş Hekimliği Fakültesi, \\ Protetik Diş Tedavisi AD, Erzurum \\ TIf: 5544200442 \\ e-mail: ozlem_ozbayram@hotmail.com
}

